\title{
ИСПОЛЬЗОВАНИЕ АПРИОРНЫХ ДАННЫХ ПРИ СОЗДАНИИ СЕЙСМО-ТОМОГРАФИЧЕСКОЙ МОДЕЛИ ХИБИНСКОГО МАССИВА
}

\author{
А. М. Жирова \\ Геологический институт Кольского научного центра РАН, г. Anатиты
}

Поступила в редакцию 19 июля 2018 г.

\begin{abstract}
Аннотация: целью исследования является построение априорных ограничений, накладываемых на модель в ходе решения обратной сейсмической задачи. Для этого проанализировань петрофизические материаль, касаюшиеся основных классов пород, распространенных по поверхности Хибинского массива и его обрамления. Выполнены малоглубинные сейсмо-томографические исследования на основе коротких (менее 2 км) годографов первых вступлений сейсмических волн. В рамках сейсмо-томографических исследований проведена подготовка детальных сейсмических данных МОВ (метода отражённых волн) и рассчитана статическая поправка за ЗМС (зону малых скоростей). Также выполнен предварительный статистический анализ сейсмических данных. Рассчитаны начальные скоростные модели, необходимые для малоглубинного сейсмотомографического моделирования. Подобран критерий остановки итеративного процесса и оптимальный параметр регуляризачии. В результате построена детальная скоростная модель

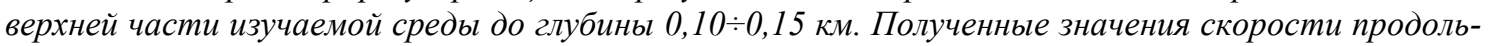
ных волн использованы в качестве граничных условий, накладываемых на 3D-модель на основном этапе сейсмического моделирования.
\end{abstract}

Ключевые слова: априорные данные, петрофизические свойства, скорость продольных волн, сейсмическая томография.

\section{THE USE OF A PRIORI DATA FOR THE CONSTRUCTION OF A SEISMIC TOPOGRAPHIC MODEL OF THE KHIBINY MASSIF}

\begin{abstract}
: the aim of the study is to construct the a priori constraints imposed on the model at the solving the inverse seismic problem. For the petrophysical materials are analyzed concerning the main classes of rocks distributed over the surface of the Khibiny massif and its surroundings. Shallow seismic tomography studies are performed on the basis of short (less than $2 \mathrm{~km}$ ) first-arrivals curves of seismic waves. In the seismic tomography studies, the detailed seismic data of MOV (reflected wave method) are prepared and a static correction for LVZ (low-velocity zone) is calculated. Preliminary statistical analysis of seismic data is also carried out. Initial velocity models necessary for shallow seismic tomographic modeling are calculated. The criterion for stopping the iterative process and the optimal regularization parameter are searched. A detailed high-velocity model of the upper part of the studied medium (to a depth of $0.10 \div 0.15 \mathrm{~km})$ is constructed as a result. The obtained values of the velocity of longitudinal waves are used as boundary conditions imposed on the 3D-model at the main stage of seismic modeling.

Keywords: a priori data, petrophysical properties, velocity of longitudinal waves, seismic tomography.
\end{abstract}

\section{Введение}

Обратные задачи геофизики, как известно, являются некорректными. Учёт априорных данных наиболее важный приём, повышающий устойчивость их решения. В работах различных авторов используется априорная информация в зависимости от особенностей самой задачи [1-9]. В процессе сейсмотомографического моделирования априорные сведения о свойствах пород играют большую роль. Это связано с тем, что обратная кинематическая задача сейсмометрии решается в линеаризованной постановке, то есть на искомую модель накладывается ограни- чение, связанное с малостью отличия начальной модели от искомой. А это, в свою очередь, приводит к большому весу самих начальных скоростных моделей в ходе решения обратной задачи.

Для построения начального приближения на практике используют усредненную $1 \mathrm{D}$-модель. Но на основе привлечения комплекса петрофизических данных и аппарата малоглубинной томографии, становится возможным построение 2D-модели среды и её использование в качестве стартового приближения для решения обратной 3D-задачи. В связи с этим в настоящей работе приводится методика построения 
априорных ограничений, налагаемых на распределение упругих характеристик в верхней части модели Хибинского массива и обрамления. Обратная 3Dзадача построения объемной скоростной (и комплексной) модели названных выше объектов в такой постановке ранее уже была решена авторами $[10,11,12]$, однако за недостатком места предлагаемая методика не была освещена в цитированных работах. В данной публикации восполняется этот важный аспект сейсмотомографического моделирования.

\section{Методика построения начальной модели}

Методически процесс построения граничных условий заключался в выполнении следующих этапов:

1. Обобщение скоростных характеристик пород по данным лабораторных измерений.

2. Подготовка детальных сейсмических данных MOB и введение статической поправки за зону малых скоростей.

3. Статистический анализ сейсмических данных MOB.

4. Расчёт начальных скоростных моделей для малоглубинного сейсмо-томографического моделирования.

Ниже детально описаны все предложенные технологические приемы.

\section{1. Обобщение скоростных характеристик} пород по данным лабораторных измерений

Скоростные свойства пород Хибинского массива и обрамления изучались на протяжении всего периода исследования данного региона [13-22]. Лабораторные измерения на образцах выполнялись по методике насыщения образцов жидкостью. Упругие параметры определялись, как правило, на образцах, изготовленных из невыветрелых пород. Анализ и обобщение петрофизических материалов, касающихся основных классов пород изучаемого региона, выполнено в работах $[23,24]$. Эти данные вошли в табл. 1 в виде усредненных значений скорости по комплексам пород.

Таблица 1

Средние скорости продольных волн в породах Хибинского массива и его обрамления

\begin{tabular}{|l|c|}
\hline \multicolumn{1}{|c|}{ Порода } & $\begin{array}{c}\text { Скорость продоль- } \\
\text { ных волн, км/с }\end{array}$ \\
\hline Гранодиориты, тоналиты & 4,63 \\
\hline Тоналиты, гнейсы & 5,07 \\
\hline Метавулканиты & 5,67 \\
\hline Габброиды & 6,18 \\
\hline Нориты, габбро-нориты, диориты & 6,24 \\
\hline $\begin{array}{l}\text { Имандра-Варзуга (осадочно- } \\
\text { эффузивные) }\end{array}$ & 5,72 \\
\hline Имандра-Варзуга (эффузивные) & 6,34 \\
\hline Перидотиты & 6,85 \\
\hline Щелочные ультрамафиты & 7,49 \\
\hline Апатитовая руда & 4,73 \\
\hline Хибинит & 4,85 \\
\hline Фойяит & 5,06 \\
\hline Лявочоррит & 5,76 \\
\hline Рисчоррит & 5,80 \\
\hline Ийолиты, уртиты & 6,03 \\
\hline
\end{tabular}

Заметно, что среди пород массива наибольшими значениями скорости упругих волн отличаются фоидолиты и составляют $6,03 \mathrm{kм} / \mathrm{c}$. Понятно, что в данную цифру усреднённо входят все разности ийолитов и уртитов, отличающиеся по составу. Нефелиновые сиениты отмечаются наименьшими значениями скорости, среди которых самыми малыми и близкими являются величины скорости хибинитов $(4,85 \mathrm{\kappa M} / \mathrm{c})$ и фойяитов $(5,06$ км/с). Несколько более высокие значения имеют лявочорриты $(5,76 \mathrm{\kappa м} / \mathrm{c})$ и рисчорриты $(5,80 \mathrm{\kappa м} / \mathrm{c})$. Что касается пород обрамления массива, заметно, что самые низкие значения соответствуют комплексу гранодиоритов и тоналитов $(4,63$ км/с) и комплексу тоналитов и гнейсов $(5,07$ км/c), в то время как наиболее высокие - щелочным ультрамафитам $(7,49$ км/c), перидотитам расслоенного интрузивного комплекса $(6,85$ км/с) и эффузивам Имандра-Варзуги (6,34 км/с).

На следующих этапах петрофизические данные были дополнены и пространственно увязаны с результатами малоглубинного сейсмо-томографического моделирования, основанного на материалах детальных сейсмических работ МОВ, полученных в

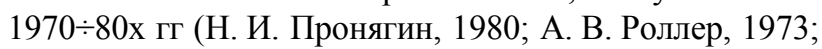
А. В. Роллер, 1976), и относящихся к поверхности массива и к области вблизи неё. С помощью малоглубинного моделирования свойства пород уточнены и дополнены результатами обращения коротких (до 2 км) годографов сейсмических волн. Тем самым получено скоростное распределение, увязанное пространственно и соотнесенное с породами Хибинского массива и обрамления.

\section{2. Подготовка детальных сейсмических данных МОВ и введение статической поправки за ЗМС}

Подготовка данных включала в себя: выделение в пределах региона семи детализированных участков и разбиение, связанных с ними сейсмических данных (координат и времён пробега сейсмических волн) на отдельные выборки; создание выборок, включающих только те данные, которые связаны с малыми (до 2 км) расстояниями «взрыв-прибор»; ввод во времена пробега волн статической поправки за ЗМС.

Необходимость выделения детализированных участков связана с неравномерностью распределения сейсмического материала. В противном случае задача обращения данных была бы сильно недоопределённой, а результат содержал бы большое количество пустот. Результат разбиения на участки представлен на рис. 1. Построение начальных и результативных скоростных моделей в рамках малоглубинной томографии производилось для каждого из участка раздельно.

Отсчитанное на сейсмограммах время пробега полезных волн не может быть непосредственно использовано для построения сейсмических разрезов. Это связано с тем, что все существующие способы обработки основаны на некоторых упрощенных предположениях о строении среды. Возникает необходимость 


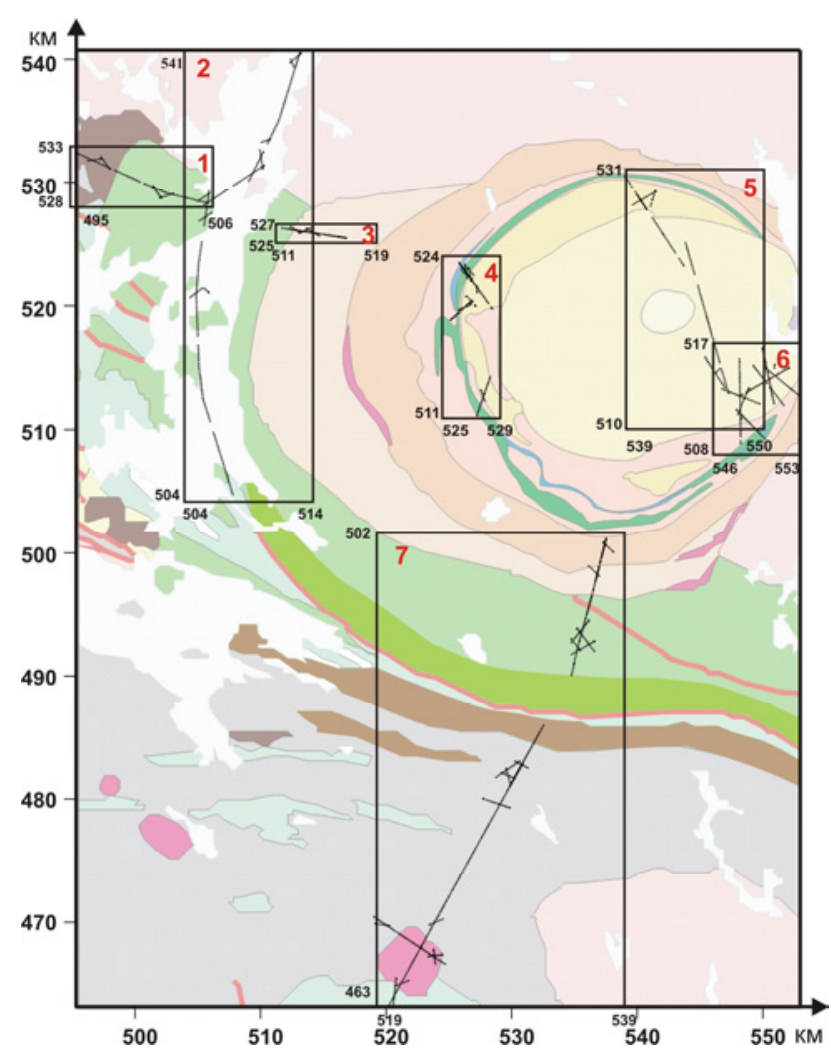

Puc.1. Схематическая геологическая карта Хибинского массива и его обрамления с вынесенными детализированными участками: 1 - Риж-губа, 2 - Имандра, 3 - Гольцовка, 4 Куэльпорр, 5 - Коашкар, 6 - Суолуайв, 7 - Салмагора.

исправления наблюдённого времени пробега волны, вызванного отклонением реальных условий наблюдений от предполагаемых. Для этой цели в наблюдённое время вводятся статические поправки. В районе Хибинского массива ЗМС представляют собой моренные отложения. Для определения характеристик ЗМС использовались результаты специальных полевых работ - наблюдений методом преломленных волн (МПВ) на пунктах взрыва, выполненные рядом исследователей при полевых работах в районе Хибинского массива (Н.И. Пронягин и др., 1980; А.В. Роллер и др., 1973; А.В. Роллер и др., 1976).

При расчёте параметров ЗМС использованы различные методы интерпретации годографов: метод встречных годографов, разностного годографа и по отдельным участкам, там, где таковые имеются, использованы нагоняющие годографы, поскольку их наличие существенно упрощает задачу определения параметров ЗМС, а также повышает её достоверность. Метод разностного годографа позволяет проконтролировать корреляцию волн при построении годографов, даёт возможность точнее определить мощность ЗМС. Для надёжности результатов производилось увязывание годографов ЗМС и соответствующих им годографов целевых волн, а также сопоставление вычисленных по ним значений граничной скорости. В результате расчётов получены значения скорости ЗМС, мощности ЗМС и поправки времени за ЗМС.
Таким образом, были рассчитаны опорные поправки к временам пробега сейсмических волн на отдельных участках профилей и в районе пунктов взрывов. Для того чтобы учесть поправки к временам пробега всех целевых волн, значения поправки интерполированы в те области, где данные о ЗМС отсутствуют. Интерполяция произведена простейшим крайгингом, учитывающим в виде весовой функции расстояния до точек с известными значениями искомого параметра. В результате построены плановые карты изолиний поправки за ЗМС и исправленные с учётом этой поправки значения времён пробега для каждого участка. Карта изолиний ЗМС для участка Коашкар приведена на рисунке 2.

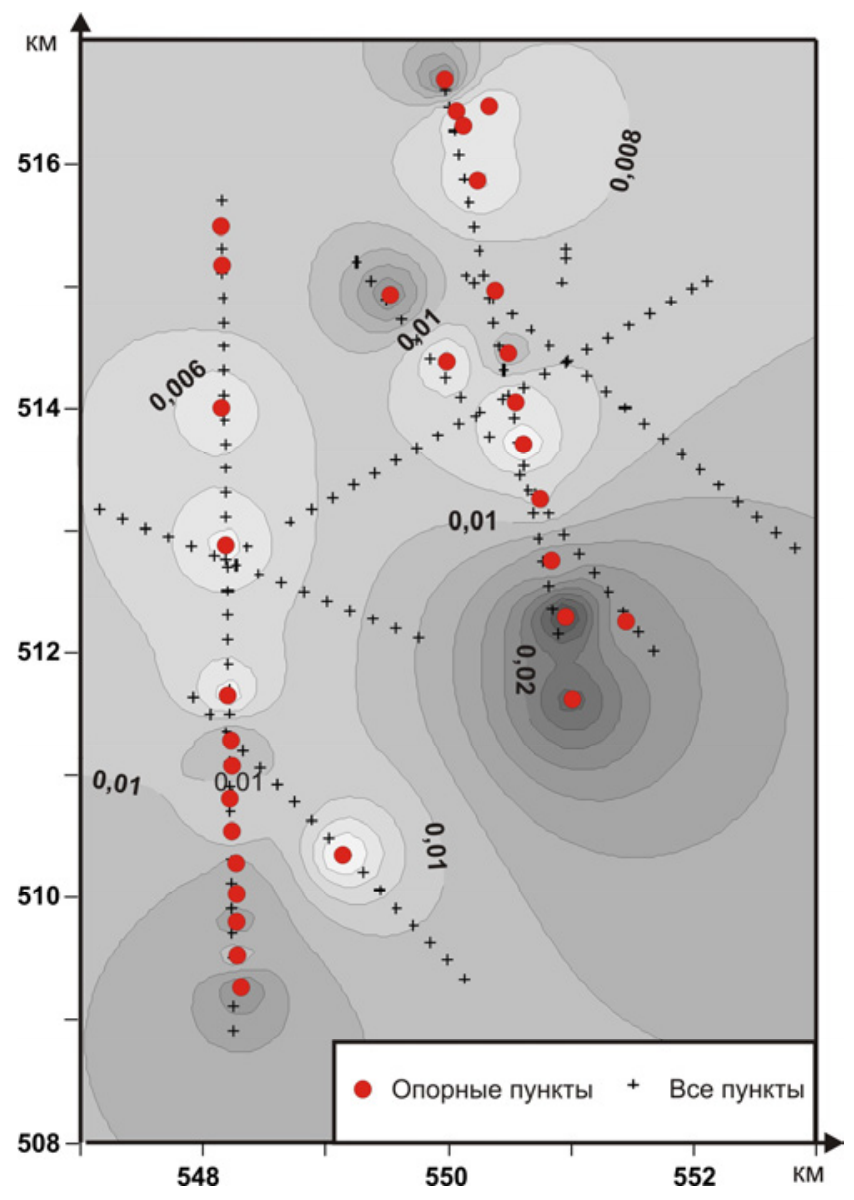

Puc.2. Изолинии поправки за ЗМС (в секундах).

\section{3. Статистический анализ сейсмических данных МОВ}

Следующим этапом предварительной подготовки сейсмического материала к малоглубинному сейсмотомографическому исследованию является статистический анализ коротких лучей МОВ (менее 2 км). Для этих данных, в количестве равном 1827 луча, проанализирован закон распределения невязки времени и решён вопрос о статистической корректности использованных данных. При этом в качестве функции, аппроксимирующей сводный годограф использована линейная функция. Для проверки закона распределе- 
ния невязок времени предварительно построены гистограмма частости невязок, а также графики накопленной частости случайной величины и интегральной функции нормального распределения. Анализ годографов первых вступлений коротких волн проведён методом скользящего окна в интервале 1 км с перекрытием в половину длины. Вся область временного поля разбита на 3 части, внутри каждой, из которых произведён расчёт локальных характеристик: дисперсии и стандартного отклонения. Оставшиеся после анализа сейсмические данные не несут больших погрешностей и модели, построенные в дальнейшем на их основе, в этом смысле являются достоверными.

\section{4. Расчёт начальных скоростных моделей для малоглубинного сейсмо- томографического моделирования}

На основе средних значений скорости продольных волн (табл. 1), базирующихся на петрофизических сведениях, необходимо было получить средневзвешенные значения скорости пород для каждого из семи детализированных участков, выделенных в исследуемом регионе. Расчёт скорости продольных волн произведён с учётом весов. В качестве последних использованы значения, соответствующие количеству ячеек, приходящихся на каждый комплекс пород в пределах участка. В результате получены распределения усреднённых значений скорости, принятые в качестве стартовых моделей на этапе малоглубинного сейсмотомографического моделирования. Результаты этих расчётов представлены в табл.2.

Таблица 2

Средневзвешенные значения скорости исследуемых участков

\begin{tabular}{|c|c|}
\hline Участок & $\begin{array}{c}\text { Скорость продольных } \\
\text { волн, км/с }\end{array}$ \\
\hline Гольцовка & 5,04 \\
\hline Куэльпорр & 5,79 \\
\hline Суолайв & 5,19 \\
\hline Салмагора & 5,45 \\
\hline Риж-Губа & 6,14 \\
\hline Коашкар & 5,24 \\
\hline Имандра & 5,51 \\
\hline
\end{tabular}

Приведённые данные демонстрируют основные особенности поверхностных скоростных неоднородностей пород: максимальные значения скорости принадлежат участкам Риж-губа и Куэльпорр, а минимальные - участкам Гольцовка, Суолуайв и Коашкар. Высокие значения скорости для Риж-губы объясняются максимальным весом в общей совокупности таких высокоскоростных пород, как эффузивы Имандра-Варзуги со средней скоростью, равной 6,34 км/с, и габброиды со средней скоростью 6,51 км/с. Что касается Куэльпорра, то участок целиком располагается в пределах Хибинского массива и содержит породы с относительно высокими значениями скорости: ийолиты и уртиты со средней скоростью 6,03 км/с, рисчорриты - 5,80 км/с и лявочорриты $-5,76$ км/с. В нём практически отсутствуют породы с низкими значениями скорости, такие как фойяиты и хибиниты. К участкам, для которых получены самые низкоскоростные начальные модели, отнесены: Гольцовка, который почти полностью приходится на хибиниты (средняя скорость - 4,85 км/с), а также Коашкар и Суолуайв с максимальным весом фойяитов (средняя скорость $-5,06 \mathrm{kм} / \mathrm{c}$ ). Что касается относительно низких средневзвешенных значений скорости на участке Имандра, то это объясняется тем, что наряду с высокоскоростными эффузивами ИмандраВарзуги, участок содержит и низкоскоростные породы комплекса обрамления - гранодиориты, тоналиты (средняя скорость - 4,63 км/с). Таким образом, на основе анализа априорных петрофизических материалов и знания геологии изучаемого района, получены начальные скоростные модели, необходимые для малоглубинного сейсмо-томографического исследования.

\section{Численное решение обратной кинематической задачи}

При решении трёхмерной обратной кинематической задачи для верхней части исследуемого региона использован современный алгоритм обращения времён пробега рефрагированных волн на базе пакета программ Firstomo [25]. Задача малоглубинной сейсмической томографии решена на основе подобранной расчётной сети $(0,2 \times 0,2 \times 0,05$ км). При выборе критерия остановки итеративного процесса учитывалась погрешность исходных данных. Для описания погрешности во временном поле использована величина шага квантования и учтён характер исходного материала (плотность покрытия лучами среды). За норму невязки и критерий остановки итеративного процесса принят момент резкого изменения градиента невязок.

Для всех детальных участков исследуемого региона построены сейсмо-томографические модели, при этом каждой модели соответствует своя погрешность. Установлено, что резкое скачкообразное изменение невязки достигается уже после второй итерации. Большие значения погрешности характерны для моделей участков, отличающихся сложностью рельефа, большими перепадами высот и пересекающих породы как Хибинского массива, так и его обрамления (участки Салмагора и Гольцовка).

Для уменьшения расхождения между теоретическими и наблюдёнными годографами произведён подбор оптимального параметра регуляризации. Исследования проведены на основе участка Гольцовка, который в геологическом отношении пересекает массивные и трахитоидные хибиниты и небольшой участок комплекса эффузивных пород Имандра-Варзуга. Использование аппарата регуляризации ведёт к сглаживанию аномалий скорости, устранению её сильных дисперсий. С другой стороны, излишняя гладкость моделей приводит к уменьшению их разрешения (потере части информации), а на этапе расчёта прямой задачи - к сильной сглаженности теоретических годографов и к увеличению невязок за счёт расхождения 
наблюдённых и теоретических годографов. Выбор оптимального значения параметра регуляризации на основе модельных вычислений для достижения оптимального разрешения модели и, в то же время, её устойчивости - является важной задачей сейсмотомографического моделирования. Произведены расчёты скоростных моделей с параметрами регуляризации 0,$1 ; 0,01$ и 0,001. При уменьшении параметра регуляризации до 0,001 в характере изменения среднеквадратичной невязки наблюдается нестабильность и большая дисперсия значений.
На рис. 3 изображен горизонтальный срез модели на уровне 0,250 км при параметрах 0,1 и 0,01. Результаты, полученные при меньшем значении параметра регуляризации, отличаются хаотичной сменой положительных и отрицательных ложных аномалий, ростом дисперсии значений скорости и их нереалистичным диапазоном. Т.е. при уменьшении параметра регуляризации даже до значения 0,01 решение «рассыпается». Поэтому сделан вывод о целесообразности использования параметра регуляризации, равного 0,1 .

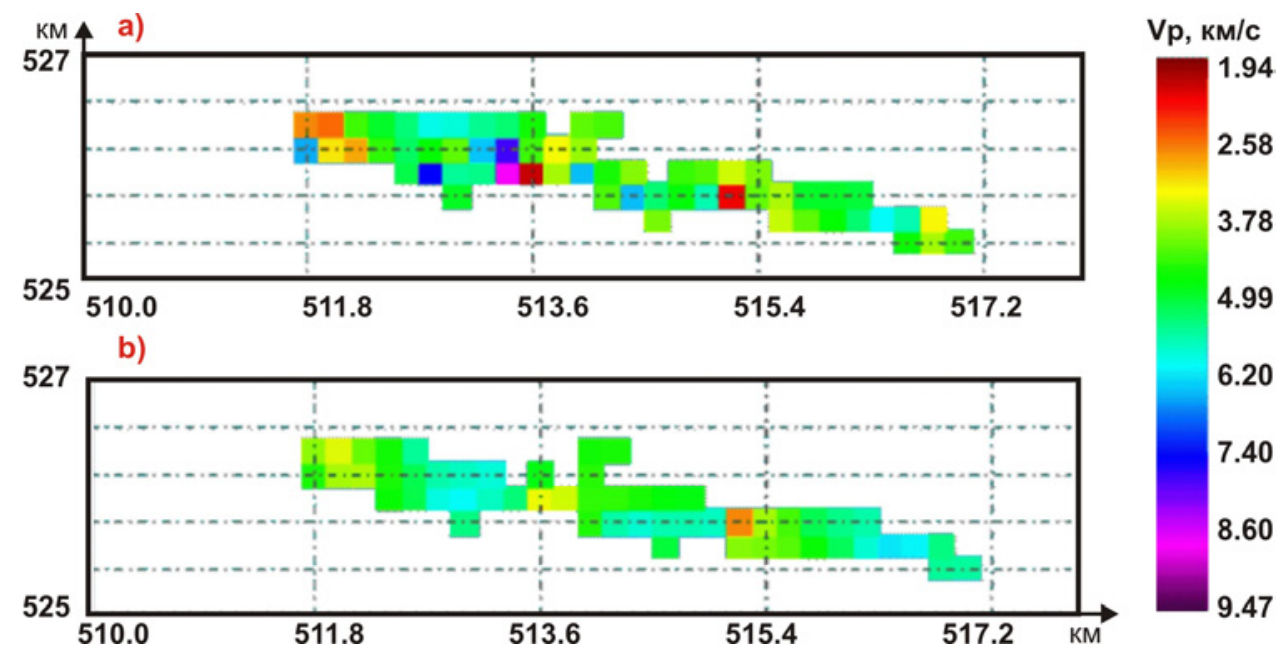

Puc.3. Скоростные модели по участку Гольцовка, рассчитанные на шестой итерации с параметром регуляризации $0,01(\mathrm{a})$ и $0,1(б)$, соответствующие горизонтальному сечению на глубине 0,250 км.

\section{Обсуждение результатов}

В результате детального сейсмо-томографического моделирования получены распределения значений скорости продольных волн пород, относящихся к приповерхностной части изучаемой среды $(0,10 \div 0,15$ км глубины). Рассчитанные характеристики пород увязаны пространственно и соотнесены с геологией района, породами Хибинского массива и его обрамления. Построены усредненные характеристики скорости для каждого комплекса пород. В качестве примера сейсмо-томографических расчётов отобран наиболее сложный с точки зрения рельефа участок Суолуайв. Горизонтальные срезы построенной модели характеризуются фрагментарностью, что объясняется сложностью рельефа участка Суолуайв. Участок пересекает различные комплексы пород. В южной и центральной его частях распространены фойяиты. На севере исследуемый участок связан с лявочорритами, рисчорритами и слегка касается фоидолитов. Полученные значения скорости распределены по комплексам пород, условно полагая, что контакты вышеперечисленных пород вертикальны от поверхности до глубин проникновения лучей. В результате установлено уменьшение скорости на нижних горизонтах рельефа, что соответствует существующему представлению о распределении свойств пород с точки зрения современной динамической геоморфологии [26]. Процессы денудации, длящиеся в регионе свыше
300 млн. лет, ведут к разрушению трещиноватых, менее плотных пород, обладающих меньшими прочностными свойствами. Поэтому в верхних горизонтах породы характеризуются высокими значениями упругих и плотностных свойств, нежели в низинах и долинах рек, которыми изрезаны Хибины, в том числе и участок Суолуайв. Комплекс фойяитов разбит на два подкомплекса с различными свойствами и различным распространением в пределах участка. По результатам малоглубинной томографии в низинах рельефа скорость фойяитов составляют в среднем 4,946 км/с, на вершинах - равна 5,329 км/с. Средняя скорость лявочорритов составляет 5,426 км/с. Рельеф участка Суолуайв, с вынесенными точками, в которых рассчитаны средние значения скорости для разных комплексов, приведён на рис.4.

Таким образом, установлено, что для участков со сложным рельефом, большими перепадами высотных отметок, одним из примеров которых является участок Суолуайв, дополнительная дисперсия значений скорости в пределах одной и той же породы вносится за счёт различия свойств пород на вершинах гор и в низинах, долинах рек. Как правило, верхние горизонты пород характеризуются высокими значениями скорости, а нижние горизонты - пониженными значениями. Расчёты скорости продольных волн и соотнесение их с комплексами пород произведены для каждого детального участка. 


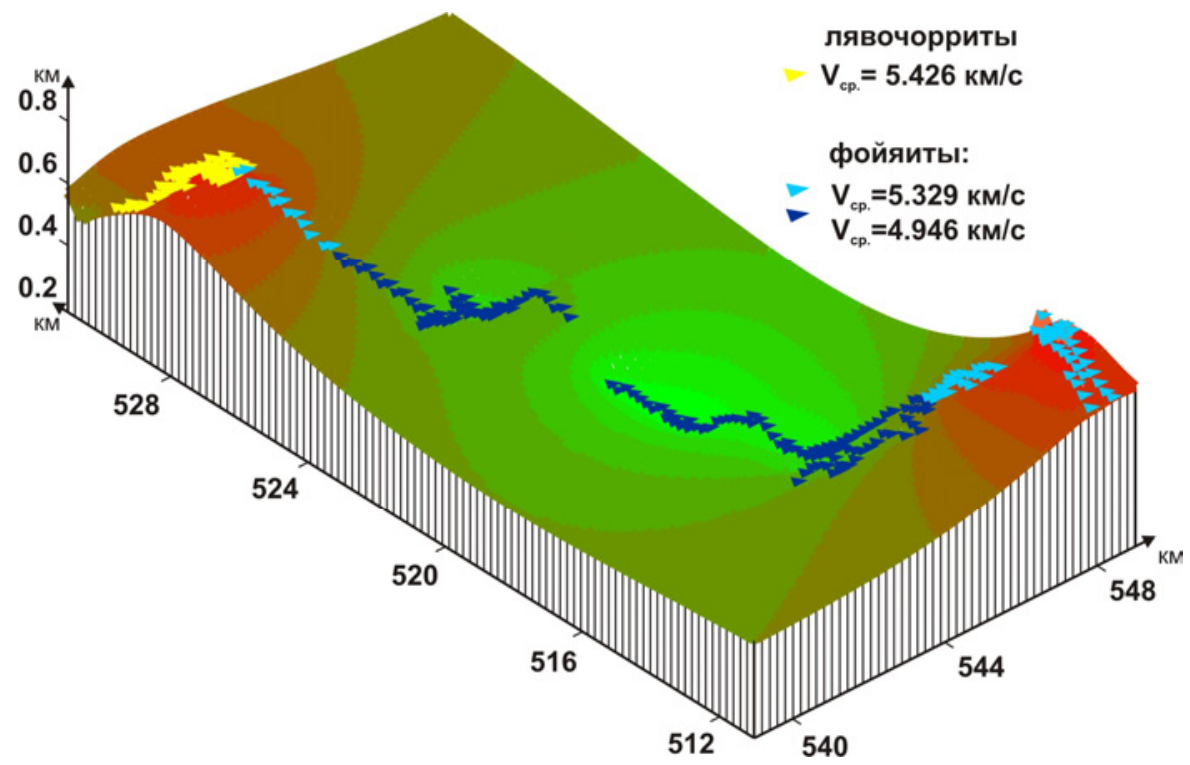

Puc.4. Рельеф участка Суолуайв в 3D-изображении с вынесенными расчётными значениями скорости различных комплексов пород.

\section{Заключение}

В результате малоглубинной сейсмической томографии получены априорные скоростные данные, опирающиеся с одной стороны на петрофизические свойства пород и руд Хибинского массива и пород, соответствующих комплексам обрамления [13-22], а с другой - на результаты детальных сейсмических исследований МОВ, относящиеся к поверхности массива и к области вблизи неё $[23,24,27,28]$. Эти данные, представляющие собой наиболее достоверную детальную приповерхностную модель скорости до глубины $0,10 \div 0,15$ км, задаются в виде граничных условий, налагаемых на 3D-начальную модель на основном этапе моделирования - этапе решения обратной комплексной задачи. Построенные априорные ограничения на распределение упругих характеристик в верхней части стартовой модели являются неизменными в ходе последующего моделирования строения среды [10-12], что и позволяет повысить достоверность результатов. Отметим, что обратная сейсмическая задача для Хибинского массива и окружающих объектов в такой постановке решена впервые.

\section{ЛИТЕРАТУРА}

1. Комплексная интерпретация данных гравиметрии, сейсмометрии и геотермии / А. Ф. Буянов [и др.] // Геофизический журнал. - 1989. - Т. 11. - № 2. - С. 30-39.

2. Three-dimensional modelling of the Lapland Granulite Belt and adjacent structures of the Baltic Shield from geophysical data / A. F. Buyanov [et al.] // Geology of the Eastern Finnmark - Western Kola Peninsula Region: collection of proceedings of the 1st. International Barents Symposium «Geology and Minerals in the Barents Region». «Norges Geologiske Undersokelse. Special Publication». Kirkenes: Norges Geologiske Undersokelse, 1995. - C. 167-178.

3. Crustal structure of the Baltic shield along the Pechenga Kostomuksha - Lovisageotraverse / F. P. Mitrofanov [et al.] // International Geology Review. - 1998. - V. 40. - №11. - P. 990-997.
4. Глазнев, В. Н. Комплексные геофизические модели литосферы Фенноскандии / В. Н. Глазнев. - Апатиты: КаэМ, 2003. $-252 \mathrm{c}$.

5. Система интерпретационной обработки сейсмических 2D/3D/3C данных prime (прайм) / О. А. Силаенков [и др.] // Экспозиция Нефть Газ. - 2014. - №6(38). - С. 6-7.

6. Avaz-инверсия по схеме Байеса с ограничением модели для изучения зон трещиноватости / Ц. Чжаоюнь [и др.] // Геофизика. - 2014. - №5. - С. 83-87.

7. Построение анизотропной глубинно-скоростной модели для проведения миграционных преобразований по данным одного из месторождений Восточной Сибири / А. С. Сорокин [и др.] // Нефтяное хозяйство. - 2015. - №12. - С. 44-47. 8. Опыт построения трехмерной сейсмо-плотностной модели по скоростным разрезам ГСЗ / И. В. Ладовский [и др.] // Уральский геофизический вестник. - 2016. - №2 (28), - С. $108-119$.

9. Oshkin, A. N. Crosshole seismic: features of the initial models design / A. N. Oshkin, M. A. Shishkina, V. A. Struchkov // Engineering geophysics 2017: collection of proceedings of the 13th Conference and Exhibition. Kislovodsk: EAGE, 2017. - DOI: 10.3997/2214-4609.201700414.

10. Глазнев, В. Н. Новые данные о глубинном строении Хибинского и Ловозерского массивов, Кольский полуостров / В. Н. Глазнев, А. М. Жирова, А. Б. Раевский // ДАН. - 2008. - Т. 422. - № 3. - С. 391-393.

11. Модель формирования Хибино-Ловозерского рудоносного вулкано-плутонического комплекса / А. А. Арзамасцев [и др.] // Геология рудных месторождений. - 2013. - Т.55. №5. - С. 397-414.

12. Глазнев, В. Н. Сейсмо-плотностная модель гигантских щелочных массивов Хибин и Ловозера (Кольский полуостров) / В. Н. Глазнев, А. М. Жирова, А. Б. Раевский // Вопросы теории и практики интерпретации гравитационных, магнитных и электрических полей: сб. материалов 34-й сессии Международного семинара им. Д.Г.Успенского. Москва: ИФЗ РАН, 2007. - С.78-81.

13. Баюк, Е. И. Скорость упругих волн при высоких давлениях в изверженных и метаморфических породах различных регионов / Е. И. Баюк, М. П. Воларович, Л. С. Скворцова // Тектонофизика и механические свойства горных пород: 
сб. статей. - М.: Наука, 1971. - С. 127-137.

14. Галдин, Н. Е. Анизотропия скоростей упругих волн в ультраосновных породах Кольского полуострова / Н. Е. Галдин // Тектонофизика и механические свойства горных пород: сб. статей. - М.: Наука, 1971. - С. 179-188.

15. Галдин, H. E. Физические свойства глубинных метаморфических и магматических пород при высоких давлениях и температурах / Н. Е. Галдин. - М.: Недра, 1977. - 127 с.

16. Дортман, Н.Б. Новые данные о скорости упругих волн в кристаллических породах и ее зависимость от влажности / Н. Б. Дортман, М. Ш. Магид // Сов. Геология. - 1968. - №5. - C. 123-129.

17. Игнатьева, T. С. Физические свойства пород и руд месторождений апатита / Т. С. Игнатьева // Опыт применения радиоактивных и других физико-химических методов при поисках и разведке руд нерадиоактивных элементов: сб. статей. - Л: Недра, 1967. - С. 112-123.

18. Петрофизика кристаллических пород рудных районов Кольского полуострова / В. А. Тюремнов [и др.] - Л.: Наука, 1982. - 120 с.

19. Распределение и корреляция показателей физических свойств горных пород: Справочное пособие / М. М. Протодьяконов[и др.] - М.: Недра, 1981. - 192 с.

20. Тюремнов, В. А. Физические свойства горных пород в связи с глубинным строением структурной зоны Имандра-Варзуга (Кольский полуостров) / В. А. Тюремнов // Автореферат дисс. канд. техн. наук. - Апатиты: КФАН СССР, 1968. - $21 \mathrm{c.}$

21. Тюремнов, В. А. Геолого-геофизические условия подземной части геофизической обсерватории «Кукисвумчорр» / В. А. Тюремнов, А. И. Зубарев // Сейсмические и геодина-

Геологический институт Кольского научного иеентра Российской академии наук, г. Апатить

Жирова Анжела Максимовна, кандидат технических наук, научный сотрудник

E-mail: anzhelaz@geoksc.apatity.ru мические исследования на северо-востоке Балтийского щита: сб. статей. - Апатиты: КФАН СССР, 1979. - С. 92-96.

22. Kern, H. Seismic properties of rocks exposed in the Polar profile region / H. Kern, C. Walter, E. R. Flue // Precambrian Research. - 1993. - V.64. - №1-2. - P. 169-188.

23. Глазнев, В. Н. Использование петрофизических данных при построении объемных комплексных геофизических моделей строения уникальных щелочных массивов Кольского полуострова / В. Н. Глазнев, А. М. Жирова // Физикохимические и петрофизические исследования в науках о Земле: сб. статей. - М.: ИФЗ РАН, 2008. - С. 93-97.

24. Жирова, А. М. Использование физических свойств пород при решении комплексной задачи геофизики / А. М. Жирова, В. Н. Глазнев // Вестник МГТУ. - 2009. - Т.12. - №3. C. $403-408$.

25. Дитмар, П. Г. Нелинейная томографическая обработка сейсмических данных / П. Г. Дитмар, Ю. В. Рослов // Международная геофизическая конференция SEG-EAГО: сб. статей. - М.: Совинцентр, 1993. - С. 55.

26. Костенко, Н. П. Геоморфология / Н.П. Костенко. - М.: МГУ, 1999. - 383 c.

27. Жирова, А. М. Начальная скоростная модель при моделировании строения Хибинского массива и его обрамления / А. М. Жирова // Геология и геоэкология: исследования молодых: сб. материалов XVI конференции молодых ученых, посвященной памяти К.О. Кратца. - Апатиты: КНЦ РАН, 2005. - C. 36-39.

28. Zhirova, A. Using a priory data in the problems of seismic tomography / A. Zhirova // Problems of geocosmos: collection of proceedings of the $5^{\text {th }}$ International Conference. $-\mathrm{SPb}$.: SU, 2004. - P. 240-242.

Geological Institute, Kola Science Centre, Russian Academy of Sciences, Apatity

Zhirova A. M., Candidate of technical sciences, Scientific Researcher

E-mail: anzhelaz@geoksc.apatity.ru 